\title{
A Introdução à Qualidade no Currículo de Química Analítica: Necessidades e Motivação
}

\author{
A N TONIO J.G. DE MENDONÇA
}

\section{Introdução}

A Qualidade na sociedade moderna é uma exigência, não só às empresas mas também aos profissionais. Deste modo, as exigências colocadas aos novos licenciados vão para além dos seus conhecimentos de Qualidade adquiridos nos currículos clássicos de Química Analítica. Com efeito, as empresas procuram cada vez mais técnicos informados e/ou motivados para a Qualidade nas suas diversas componentes.

A Química Analítica é uma disciplina que processa informação, extraindo-a primeiro e fornecendo-a depois. A Qualidade da informação está relacionada com a garantia de que a informação produzida reproduz de modo fidedigno uma ou mais das características do produto analisado. Por outro lado, a qualidade do produto é sempre subjectiva e depende muitas vezes do ponto de vista do utilizador. A qualidade de um produto pode ser definida como o respeito estrito das especificações que foram elaboradas para esse produto, antes da fase de produção.

A relação entre a Qualidade em Química Analítica e a Qualidade global na empresa é muito estreita na medida em que esta última não poderá ser elevada se o(s) seu(s) laboratório(s) de Química Analítica não fornecerem respostas com qualidade.

A Química Analítica tem um papel muito importante quer ao nível da Garantia da Qualidade como do Controlo de Quali- dade. A Garantia da Qualidade é constituída por um conjunto de actividades planeadas e sistemáticas (ex: calibração de aparelhos) que uma vez integradas devem garantir que o nivel de qualidade desejado está a ser obtido. Por outro lado, no Controlo de Qualidade efectuase a monitorização rotineira de parâmetros de produtos, intermédios ou finais.

Existem excelentes manuais de Química Analítica, como o de Valcárcel [1] ou o de Kellner et al. [2], que colocam o tema da Qualidade numa posição importante. Infelizmente, nem sempre é possivel efectuar o estudo aprofundado da Qualidade no currículo de Química Analítica, sobretudo quando os alunos não pertencem a licenciaturas em Química ou em variantes desta, dado que existem outras matérias a ser leccionadas e que não podem ser menosprezadas. Valcárcel [1] sugere diferentes conteúdos a leccionar de acordo com o nivel de compreensão desejado, que ocuparão pelo menos, 20 a 30 horas, o que corresponderia na prática à ocupação quase que exclusiva de uma disciplina semestral.

A educação para a Qualidade deve iniciar-se durante a graduação e não só numa pós-graduação formal, ou numa pós-graduação obtida pela experiência da vida activa. Deste modo, apresentase aqui uma proposta para a inclusão no currículo de Química Analítica de licenciaturas, não nucleares em Química, como são os casos de Engenharia Têxtil e Engenharia do Papel, de uma Introduçăo à Qualidade.
Partindo de casos práticos como a dimensão de uma folha de papel para fotocópia ou a definição das características de uma cor, justifica-se a necessidade de normalização e daí progride-se no sentido da Qualidade em Química, figura 1. Por outro lado, se a Qualidade no laboratório está enquadrada pela norma EN ISO/IEC 17025 (Requisitos Gerais de Competência para Laboratórios de Ensaio e Calibração) a sua integração com a norma ISO 14001, referente à qualidade ambiental é sublinhada conferindo maior importância à Química Analítica, tanto no controlo estrito da qualidade dos produtos, como na qualidade ambiental.

A utilização de normas internacionalmente reconhecidas como referencial de sistemas de reconhecimento e avaliação da conformidade de produtos é uma exigência cada vez mais disseminada acompanhando a globalização da economia.

\section{Método}

Os conteúdos são leccionados em módulos (total de 5 horas), figura 1 , de modo que podem ser leccionados a alunos de outras licenciaturas, em parte ou na totalidade. Neste último caso, encontra-se o módulo sobre os sub-sistemas da qualidade em que o exemplo do HACCP [3] (Hazard Analysis and Critical Control Point, Análise de Perigos e Controlo de Pontos Críticos) pode ser leccionado a alunos de disciplinas com vertente alimentar. As principais relações 


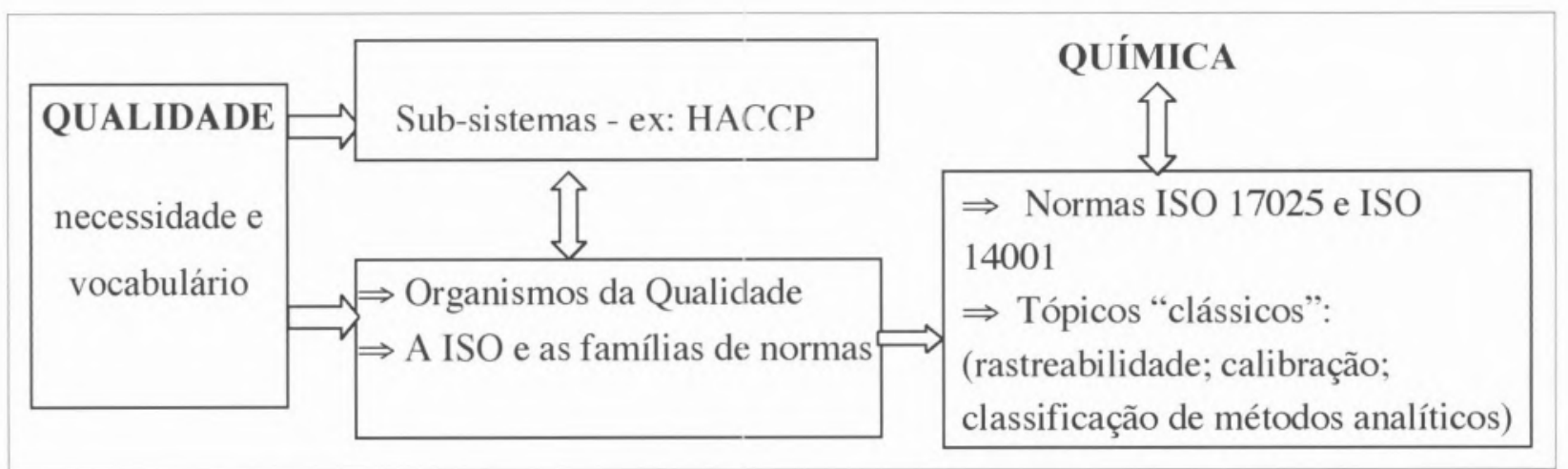

figura 1 Estrutura metodológica para uma Introdução à Qualidade em Química Analítica. HACCP (Hazard Analysis and Critical Control Point) Análise de Perigos e Controlo de Pontos Críticos. ISO (International Standards Organization) - Organização Internacional de Normalização.

existentes entre os diversos módulos são realçadas e perspectivam-se as integrações dos respectivos conteúdos teóricos num ambiente prático.

De modo a complementar as aulas é fornecido aos alunos um texto de apoio [4] sobre o conjunto das matérias dos módulos, assim como é facultada bibliografia sobre os conteúdos analisados desde o ponto de vista químico [1, 2] ou do ponto de vista das normas e da gestão da Qualidade [5 - 7].

\section{Resultados}

Os alunos apresentam-se mais motivados, aumentando a assistência e a participação nas aulas, assim como aceitam de modo mais positivo os tópicos "clássicos" sobre a Qualidade em Química Analítica.

Os alunos ficam alertados para os novos desafios da Qualidade como a certificação de pessoas como medida de reconhecimento da sua competência e/ou excelência na execução de determinados serviços.

A introdução à nomenclatura da Qualidade permite uma melhor adaptação e integração dos novos profissionais nas empresas.

\section{Conclusões}

Os alunos reconhecem a importância do tema e do conteúdo leccionado, tendo em conta a cada vez maior ligação entre a Qualidade e a Química Analítica. Deste modo propõe-se o alargamento dos temas aqui tratados a alunos de outras licenciaturas com uma adaptação mínima, nomeadamente o módulo sobre os subsistemas da qualidade que se aplicam a casos específicos, como o HACCP à indústria alimentar.

\section{Referências}

[1] - M. Valcárcel, Principles of Analytical Chemistry: A Textbook, Springer - Verlag, Berlin, Germany, 2000.

[2] - R. Kellner, J.-M. Mermet, M. Otto, H. M. Widmer, (Editors); Analytical Chemistry, Wiley-VCH, Wheinheim, Germany, 1998 .

[3] - S. Mortimore, C. Wallace, HACCP - A Practical Approach, 2nd edition, Aspen, Gaithersburg, USA, 1998.

[4] - António J. G. de Mendonça, Qualidade e Química Analítica, Universidade da Beira Interior, Covilhã, 2001.

[5] - A. Ramos Pires, Qualidade - Sistemas de Gestão da Qualidade, Edições Silabo, Lisboa, Portugal, 2000.

[6] - Norma Portuguesa 17025:2000, Requisitos gerais de competência para laboratórios de ensaio e calibração, Instituto Português de Qualidade, Lisboa, Portugal, 2000.

[7] - Norma Portuguesa 9001:2000, Sistemas de gestão da qualidade - Requisitos, Instituto Português de Qualidade, Lisboa, Portugal, 2001.

As pessoas menos familiarizadas com a ciência podem colocar, muito justamente, uma pergunta: até quando haverá progresso científico? Conta-se que na América em 1865, no tempo de Abraham Lincoln, o chefe do gabinete de patentes escreveu ao Governo uma nota informativa na qual sustentava que, dada a grande velocidade a que se davam as descobertas naquele período, o gabinete fecharia em poucos anos porque tudo o que fosse necessário descobrir, em poucos anos, de facto, seria descoberto. 